\title{
SETTING THE CONTEXT FOR OFFSHORE WIND DEVELOPMENT EFFECTS ON FISH AND FISHERIES
}

By Andrew B. Gill,

Steven Degraer,

Andrew Lipsky,

Ninon Mavraki,

Elizabeth Methratta,

and Robin Brabant

2

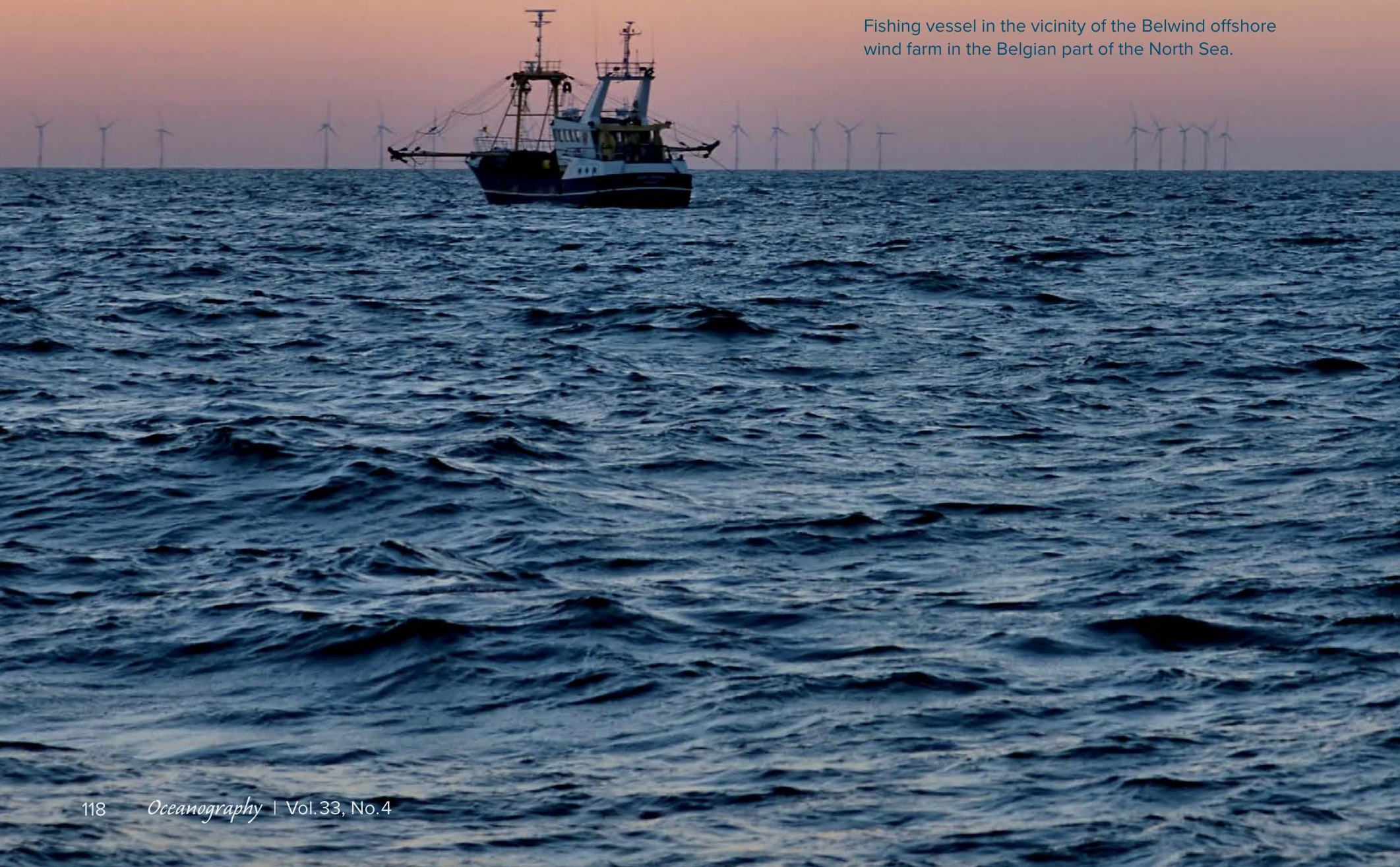

ABSTRACT. Changes to fisheries that result from offshore wind farm (OWF) installations may be considered good or bad depending on various stakeholders' perspectives. OWFs can act as artificial reefs that may benefit secondary fish production, but such effects may also have ecological consequences. The fisheries exclusion effect that turns some OWFs into no-go areas, hence effectively no-take zones, could provide resource enhancements or redistribution. However, the displacement of fishing effort may have consequences to fisheries elsewhere. Changes in the sensory environment related to sound, as well as electromagnetic fields and physical alterations of current and wind wakes, may have as yet unknown impacts on fisheries resources. Understanding the interactions among effect type, OWF development phase, and spatiotemporal population dynamics of commercial and recreational species remains challenging, exemplified by the commercial fishery lobster genus Homarus in European and North American waters. While knowledge of the interactions between resource species and OWFs is improving, there remain questions on the wider interaction between and consequences of OWFs and fisheries. Studies of this wider relevance should aim to improve understanding of the economic and societal impacts of OWFs linked to ecosystem services that support fisheries. Furthermore, assisting fisheries management and providing advice requires monitoring and survey data collection at appropriate spatiotemporal scales. This information will help to determine whether OWFs have any meaningful impact on regional fisheries, and increased investments will be needed to target scientifically appropriate monitoring of OWFs and fisheries, which is supported by better integrated policy and regulation. 


\section{INTRODUCTION}

With the increasing number of offshore wind farms (OWFs) being built and planned in several coastal zones around the world, there is a growing need to fully consider multiple use options of the marine space because some traditional uses, such as fishing, are currently regarded as mostly incompatible with OWFs. In many European countries, active fisheries methods, such as trawling, are legally banned from OWF development footprints that include $500 \mathrm{~m}$ buffers around the turbine arrays (e.g., Belgium). In countries where no legal ban exists, trawling may not take place anyway because liability and safety issues prevent fishers from entering the wind farm array (e.g., UK). Passive fisheries methods, including the use of fixed fishing gear (e.g., pots for the lobster genus Homarus), may still be used within OWFs and may thus profit from the increased abundances of large crustaceans inside (Krone et al., 2017). Hence, OWFs result in a loss of or restricted access to some traditional fishing grounds but may equally provide new opportunities to specific types of fisheries.

This differential effect resulting from the interaction between OWFs and fisheries has led to lively debate and some conflict between the two sectors. For example, protestors have used fishing vessels to obstruct pre-construction surveys in France. In the Netherlands, a fisheries action group protested against new OWFs in the North Sea. Fishing and related businesses have also petitioned federal agencies in the United States to improve inclusion of the fishing industry in the decision-making process and consider appropriate mitigation and compensation for any detrimental effects on the fisheries resources or fishers. The difficulty is that evidence is required to clearly demonstrate effects at both local and regional scales. Furthermore, some effects may be deemed positive and others negative, depending on the perspectives of various stakeholders. To obtain the most appropriate evidence critically requires improved baseline fisheries data and ongoing site and regional research and monitoring, which will require crossjurisdictional collaborations and proper resourcing. In the absence of appropriate knowledge, the effects of OWFs on fisheries is uncertain; however, the debate can be facilitated by collaboration through sectorally focused organizations.

At present, improving knowledge about how OWF developments may affect fishery resource species is directed to examining fishes' life histories and determining how the effects may act at the cellular, organismal, population, and/or ecosystem levels of organization (Gill and Wilhelmsson, 2019). Arguably, regardless of how and at what life stage the resource species is affected, what is significant to the fishery stock is whether effects are seen in catches, landings, and quality of the species. Hence, the links between the biological, ecological, and socioeconomic outcomes of the effects and the changes to the stock require better understanding. Changes in the sensory environment caused by the emission of energy from OWFs (e.g., electromagnetic fields, EMFs) and by underwater sound along with changes to the physical environment caused by the alteration of water currents and wind wakes may be regarded as significant to the fishery if they affect fish (re)production, migration, and/or distribution. As artificial reefs and (often) fisheries exclusion zones, OWF areas are contributors to locally increased attraction, concentration, and food provision for some fish species (Mavraki, 2020), with possible consequential effects to fish stocks. No OWF-related evidence currently exists regarding whether there are changes to fish production (Gill and Wilhelmsson, 2019). In the offshore oil and gas sector, increased fish production studies have focused on the trophic pathways that lead from artificial reef effects to increased fish production (Daigle et al., 2013; Dance et al., 2018; Reeves et al., 2019), and fish numbers and biomass have been shown to be greater than in nearby natural hard substrate areas
(Claisse et al., 2014). Despite this surrogate evidence, because OWF footprints are different from those of oil and gas installations, there remains uncertainty about how local ecological changes at the wind turbine scale translate to the wider ecosystem and about any consequence to resource species stock dynamics.

Although the European offshore wind industry has existed and slowly expanded for more than two decades (WindEurope, 2020), the pace and scale of growth in the industry are now at similar inflection points in Europe, the United States, and East Asia, and major policy initiatives, such as net zero or specific renewable energy targets, are either already in place or being seriously contemplated by political jurisdictions. OWF growth is reflected in increases in the pace of new wind developments, new technological advances in turbine design and power management and transmission, and a significant increase in the spatial scales of projects (GWEC, 2020). Therefore, there is now a prime opportunity and in fact a need for shared learning to best address the challenges of building the requisite scientific frameworks to apply to the effects of OWFs on fisheries that are commensurate with the scale and pace of development and the concomitant forecasted changes.

In this paper we provide an overview of likely direct effects on commercially and recreationally fished species and their fisheries, including artificial reef effect, fisheries exclusion from OWF areas and displacement to other areas, and changes in the sensory and physical energy environment (e.g., noise, EMF, currents, and wind wakes). We highlight both the complexity and the spatiotemporal variability of interactions that have been studied and where knowledge gaps remain. These gaps include a lack of an assessment of the best methods for collecting data appropriate for scaling local effects to population and ecosystem levels as well as a lack of an assessment of how important cross-boundary regional coordination of research and monitoring is to fulfilling this need. To advance the necessary 
scientific understanding of the effects of OWFs on fisheries, we also reflect on the wider societal, policy, and financial hurdles that currently hinder the efficiency and efficacy of monitoring and research programs, and propose possible solutions to overcome these hurdles.

\section{FOUR TYPES OF OFFSHORE WIND FARM EFFECTS ON FISH AND FISHERIES}

OWFs have four broad types of direct effects on fish and fisheries (Table 1): the artificial reef effect, fisheries exclusion, energy landscape effects (i.e., sound, EMF, and currents, wind wake), and fisheries displacement (Bergström et al., 2014). The first three occur at the OWF scale with possible knock-on effects at larger scales, while the fisheries displacement effect occurs at spatial scales beyond the OWF.

\section{Artificial Reef Effect}

By their presence, OWFs attract species and hence function as artificial reefs (Langhamer, 2012; Degraer et al., 2020, in this issue), potentially resulting in both benefits and adverse consequences for populations and ecosystems. Newly

TABLE 1. Distribution of the four types of effects that may occur across the three development stages of OWFs. Brackets represent potential effects. *Energy landscape includes the sensory and physical energy environment.

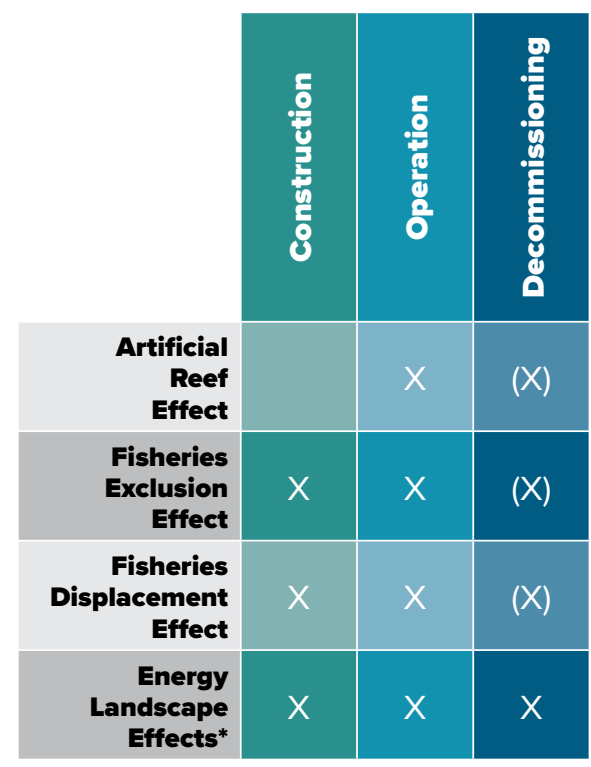

introduced turbine foundations are hard (concrete and metal) substrates that are rapidly colonized by communities of epifaunal (i.e., "fouling") species (De Mesel et al., 2015). Subsequently, mobile fauna such as crustaceans, mollusks, and fish forage and refuge near the introduced substrates, often at higher densities compared to surrounding areas (Reubens et al., 2014; Paxton et al., 2020). Increased abundance of finfish may result from redistribution of existing biomass or from increased species production, a topic hotly debated for decades (e.g., Bohnsack, 1989; Lindberg, 1997; Brickhill et al., 2005) that still requires further evidence to be deemed an effect of OWFs (Gill and Wilhelmsson, 2019). The facilitation of non-native species colonization is also possible, as has been documented for some artificial structures (Schulze et al., 2020), and for OWF turbine foundations specifically (De Mesel et al., 2015). Importantly, because the primary purpose of OWFs is not fisheries enhancement, OWFs lack the design features that are incorporated into planning artificial reefs (e.g., consideration of placement, materials; Paxton et al., 2020). Thus, caution is needed in drawing direct inference from the artificial reef literature to effects of OWFs.

\section{Fisheries Exclusion, Displacement, and Beyond}

Fisheries regulations within OWFs differ among management jurisdictions. In Belgium, access to OWFs is prohibited for all vessels except wind farm maintenance and governmental research vessels. Consequently, some fishing grounds are no longer accessible to commercial and recreational fishing. In the United Kingdom, navigation of fishing vessels and passive fishing is allowed within OWFs. This is, however, not yet common practice as there are still barriers relating to safety of navigation, lack of insurance coverage for damages to gear or vessels inside OWFs, and lack of cooperation and knowledge exchange between sectors (Gusatu et al., 2020).
Initially, OWFs in the Netherlands were inaccessible to fishing vessels; however, in 2015, the Dutch government adapted regulations to allow some types of fishing vessels and commercial ships to navigate through OWFs. Arrangements were made between the different stakeholders, and conditions for multiuse and transit of vessels were adapted based on new insights from research (https://www.msp-platform.eu/).

Although some have suggested that the absence of fishing at OWFs could lead to their functioning as marine protected areas (MPAs) (Ashley et al., 2014), OWFs are not designed as conservation management tools and therefore lack the design elements of MPAs that have successfully contributed to enhanced fishery resources (Gaines et al., 2010). Thus, it is possible that the exclusion of fishing from OWFs could have both positive and negative consequences for species and local ecosystems. On the one hand, for species whose local production is limited by fishery or bycatch mortality, increases in biomass, numerical density, and size, as well as "spillover effects," are possible (Lester et al., 2009; Harrison et al., 2012), depending on the spatial scales of closed areas and the degree of overfishing of the resource in general. A reduction in bottom towed gear (trawls and dredges) within the regulated OWFs would further likely result in reduced impacts on benthic biomass, habitat complexity, and biodiversity, all with potentially positive consequences to managed fish populations. On the other hand, fisheries exclusion within OWFs may also increase predation risk from attracted predators and fishing pressure by attracted (e.g., recreational) fisheries. Furthermore, a reduction in commercial fishing activity inside OWFs will lead to a spatial redistribution in fishing effort (i.e., fisheries displacement effect) to areas outside the wind farm (Murawski et al., 2005; De Backer et al., 2019), potentially leading to competition among fishermen and to unintended adverse interactions with other previously less impacted sensitive habitats. 
Understanding the availability and ecology of alternative fishing locations and fisheries resources is vital to determining whether displacement will have impacts (or not). Beyond fisheries exclusion and displacement, offshore wind can have other positive and negative social and economic implications for both commercial and recreational fishing communities and the extended fishing businesses they support (Hooper et al., 2017). Negative effects could include changes in shoreside infrastructure, navigation and transit radar interference, reduced efficiency in effort (e.g., through increased transit time and changes in landing locations), and effects on fisheries management (e.g., impacts to stock abundance surveys, population assessments). On the positive side, local communities could benefit from, for example, increased local investment and diversity of employment. The totality of such impacts, be it positive or negative, requires spatially explicit data and models of how species and ecosystems will respond as well as an understanding of fishing community responses in relation to the development of OWFs.

\section{Sensory and Physical Energy Environment Effects}

OWFs can change the sensory and physical energy of the environment with increased energy emissions in the form of underwater sound and vibration, EMFs, and changes in water current and wind wakes. The OWF construction phase is often characterized by high-intensity impulsive sounds from pile driving, potentially affecting fisheries resources sensitive to sound and vibration (Debusschere et al., 2014; Mooney et al., 2020, in this issue). Exposure to such sound-based energy can cause acute stress responses in species, influencing individual's behavior and physiology, and, if widespread within a species, potentially leading to reduced population growth rates (Hawkins et al., 2015). Scaling up to population-level effects requires consideration of the intrinsic population dynamics, including the mortality rates of a spe- cies that is a target for a fishery and of other species supporting them as prey. Naturally very high fecundity and mortality rates, for example, may render anthropogenic effects relatively inconsequential. The acoustic effects of OWFs on sensitive species may occur through sound emitted when the OWF is operational; however, the effect is likely restricted to masking animal communication and orientation signals, rather than causing physiological damage or permanent avoidance reactions (Popper and Hawkins, 2019).

During OWF operation, species will interact with EMFs generated by electricity transmission within the subsea cable array and the export cable to the mainland (Taormina et al., 2018; Hutchison et al., 2020b, in this issue). Species that migrate using magnetic cues, and those that orient and/or forage using electric and/or magnetic fields are of particular interest as research has shown movement and behavioral changes in response to subsea cable EMFs (Hutchison et al., 2020a; Gill and Desender, 2020).

Changes to water currents and wind wakes (i.e., the loss of kinetic energy leeward of the turbines) and their coupling to oceanographic processes may alter hydrodynamic patterns and vertical stratification, potentially over large spatial scales (Carpenter et al., 2016; SCEMFIS, 2020; van Berkel et al., 2020, in this issue). This may change the vertical and horizontal transport of nutrients to primary producers, the distribution of suspended particulates, and photic zone depth. These changes could have important implications for primary and secondary biological production (Floeter et al., 2017). Changing currents can also impact larval dispersal and distribution (Barbut et al., 2020).

\section{Time and Space Dependency of Offshore Wind Farm Effects}

The type and magnitude of OWF effects vary with the stages of offshore wind development (construction, operation, decommissioning; Table 1; Gill, 2005). While our understanding of effects during the construction and operational phases is constantly growing, little is known about the effects of decommissioning and how a post-decommissioning environment will look and function. The options for OWF decommissioning, which has only recently begun, include complete removal, partial removal, or simply leaving the infrastructure in place. Removal options will cause habitat disturbance, and all options will have unique effects on future associated fish assemblages and potentially on fisheries and fisheries resources and access to them (Fowler et al., 2018).

Knowledge of local effects on fish assemblages at individual wind farms and fisheries is increasing, particularly in the North Sea; however, effects of OWFs on fish stocks in Europe or elsewhere are poorly understood (but see De Backer et al., 2019). Similar questions regarding effects on regional production have been explored at offshore oil and gas platforms, and there has been some effort to incorporate abundance estimates measured at platforms into stock assessments (Campbell et al., 2012). Yet, even for this 60-plus year-old industry, many questions remain regarding the regional implications of local ecological effects.

Ecosystem modeling could be used to explore potential effects on regional production. Ecopath with Ecosim (EwE) modeling applied to an OWF in the English Channel suggests that a possible reef effect could increase total system biomass by $55 \%$ (Raoux et al., 2017). In the Jiangsu coastal ecosystem of China, EwE modeling indicated that OWFs may increase detritus and benefit phytoplankton, zooplankton, anchovies, and some benthic fish (Wang et al., 2019). The validity of most ecosystem modeling relies on local-scale data, but these approaches allow researchers to move beyond studying impacts on individual functional compartments of the ecosystem toward a more holistic approach and may improve insights into how OWFs affect fish productivity and hence fish stocks, with continued input from ongoing field data col- 
lection. Integrating the temporal and spatial dependency of the four OWF effect types and of the life history of, for example, commercial marine species, is complex, as illustrated by the lobster genus (Homarus) in Box 1.

\section{SOCIETAL ENGAGEMENT, MONITORING, REGULATORY FRAMEWORKS, AND INVESTMENT NEEDS}

While environmental considerations are important for understanding OWF and fisheries interactions, several other aspects of this topic need to be addressed in order to more fully establish the effects OWFs have on fisheries.

\section{Societal Engagement}

Seafood provision and a positive perception of biodiversity by society are recognized drivers for marine management worldwide (Botsford et al., 1997; Worm et al., 2009). Thus, taking an ecosystem services approach to explaining fisheries resource changes to the public could be useful. However, public participation is a crucial yet often neglected consideration in the plans for new developments in marine areas (O'Keeffe and Haggett, 2012). While fisheries changes related to OWFs can be determined scientifically (in terms of statistical, ecological, or environmental significance), to properly address whether such changes are mean- ingful to society requires the social significance of any change to be interpreted and communicated to the public (Dannheim et al., 2020). It also requires building shared-knowledge trust through collaborative research between industries and scientists. OWFs will directly or indirectly alter a range of provisioning, supporting, regulating, and cultural ecosystem services as a result of changes to the presence, abundance, and distribution of fisheries species and how fisheries and fishing communities respond to these changes (Gill and Wilhelmsson, 2019). The public will notice these shifts through changes in the availability of fresh seafood locally and nationally; preferred type, and price,

\section{Box 1. Space- and Time-Based Interactions Between Offshore Wind Farms and the Life History of the Lobster Cenus (Homarus)}

The population (or stock) of a resource species is determined by the recruitment and growth of individuals and the mortality rate from both natural and human causes. Recruitment occurs at a specific point in the life of a resource species, while growth and mortality occur at each life stage. Thus, understanding the potential causes and effects of OWFs on growth and mortality rates at the different life stages is important for recruitment and the resultant population available to be fished. OWF effects may occur during construction and/or operation phases. Processes determining growth and mortality of a species can operate at different scales, with passive and/or active dispersal and life stage duration driving spatial and temporal variation in occurrence.

The effects of an OWF on a resource species may occur at one or more life history stages, depending on spatial and temporal habitat use and requirements of the species as well as interactions with other species (e.g., predator-prey). To illustrate, the lobster genus Homarus has five distinct life stages: embryonic egg, larval zoea, early benthic juvenile (megalopa), juvenile, and adult (Figure B-1a). During the construction phase, noise and vibration disturbance from pile driving and vessel movement could influence lobsters (Roberts and Elliott, 2017). Higher sound levels in the water column may increase mortality or cause sublethal effects (e.g., developmental or behavioral) for the larval stages, while suspended sediment in the water column (turbidity) may reduce mortality because the predator's vision may be inhibited (Figure B-1b; Gill and Wilhelmsson, 2019). If there is pile driving during the construction phase, then benthic life stages may be exposed to vibration of the seabed (Figure B-1b; Roberts and Elliott, 2017).

During the OWF operational phase, the artificial reef effect and fisheries exclusion will cause spatial and temporal changes in local food opportunity (Figure B-1c; Mavraki et al., 2020), habitat availability (Krone et al., 2013), and likelihood of predation (Reubens et al., 2014; Dannheim et al., 2020). Hydrographic prop- erty changes may cause differences in passive dispersal for the pelagic zoea larval stage (Figure B-1b; Floeter et al., 2017). For the benthic megalopa stage, the priority is finding shelter prior to molting (Wahle, 1992). The early benthic juvenile stage is considered site attached, as the animals occupy shelter-providing substrata such as cobble-boulder or muddy seabed into which they can burrow (Figure B-1b,c; Cooper and Uzmann, 1980). OWF foundations and scour material may alter the availability of suitable habitat as can rock dumps or placement of concrete mattresses for protecting subsea cables in hard seabed areas (Figure B-1c). Homarus spp. juveniles are very vulnerable to predation and only leave the burrow if forced out. Therefore, exposure of burrowing juveniles because of shelter limitation, or when in suitable shelters via increased vibration transmitted through the seabed or EMF from buried cables, may be relevant to survival (Figure B-1b). Once juveniles have grown large enough to avoid (most) predators, they begin migratory and/or long-distance foraging behavior. Adults usually travel several kilometers, with $H$. americanus moving over larger distances than the European lobster $H$. Gammarus (Wahle, 1992). During this stage, they inhabit crevices in sandy and rocky substrata that are similar to some scour protection (Figure B-1c). The distance traveled to preferred habitat will also vary by gender, as egg-carrying females are less active than those searching for a mate, and Homarus spp. perform seasonal migrations from deep to shallower waters (Cooper and Uzmann, 1980; Moland et al., 2011). While moving around, adult American lobster (H. americanus) may respond to electromagnetic fields emitted by subsea cables (Hutchison et al., 2020a). There are therefore clear conceptual pathways that link OWF effects on lobster early life stages (that last days to a few years) and adult stages (tens of years) to potential effects at the level of the population. However, a clear mechanistic understanding of these cause-effect relationships requires further targeted study. 
size, and quality of food; and/or regularity of supply. Improved understanding of the economic and societal impacts of the OWF on fisheries is needed to assist energy policy development, planning, decision-making, and potential mitigation suggestions (Hooper et al., 2017).

Effective management of the marine environment requires appropriately scaled and focused data collection to ensure that meaningful changes attributable to OWFs are acceptable to society (Wilding et al., 2017). The present-day debate between fisheries and OWFs highlights the need for (re)directing knowledge advancement (both monitoring and research) toward addressing societal concerns, which fundamentally relate to fisheries (e.g., through effects on stock size, structure, and/or distribution). Current monitoring and research programs primarily target observing the aggregate effects of OWFs on individual receptors rather than determining the underlying cause-effect pathways; exceptions include the Belgian WinMon.BE monitoring program (Degraer et al., 2019) and the Dutch WOZEP research program (Dutch Ministry of Infrastructure and the Environment, 2016). The conflict between
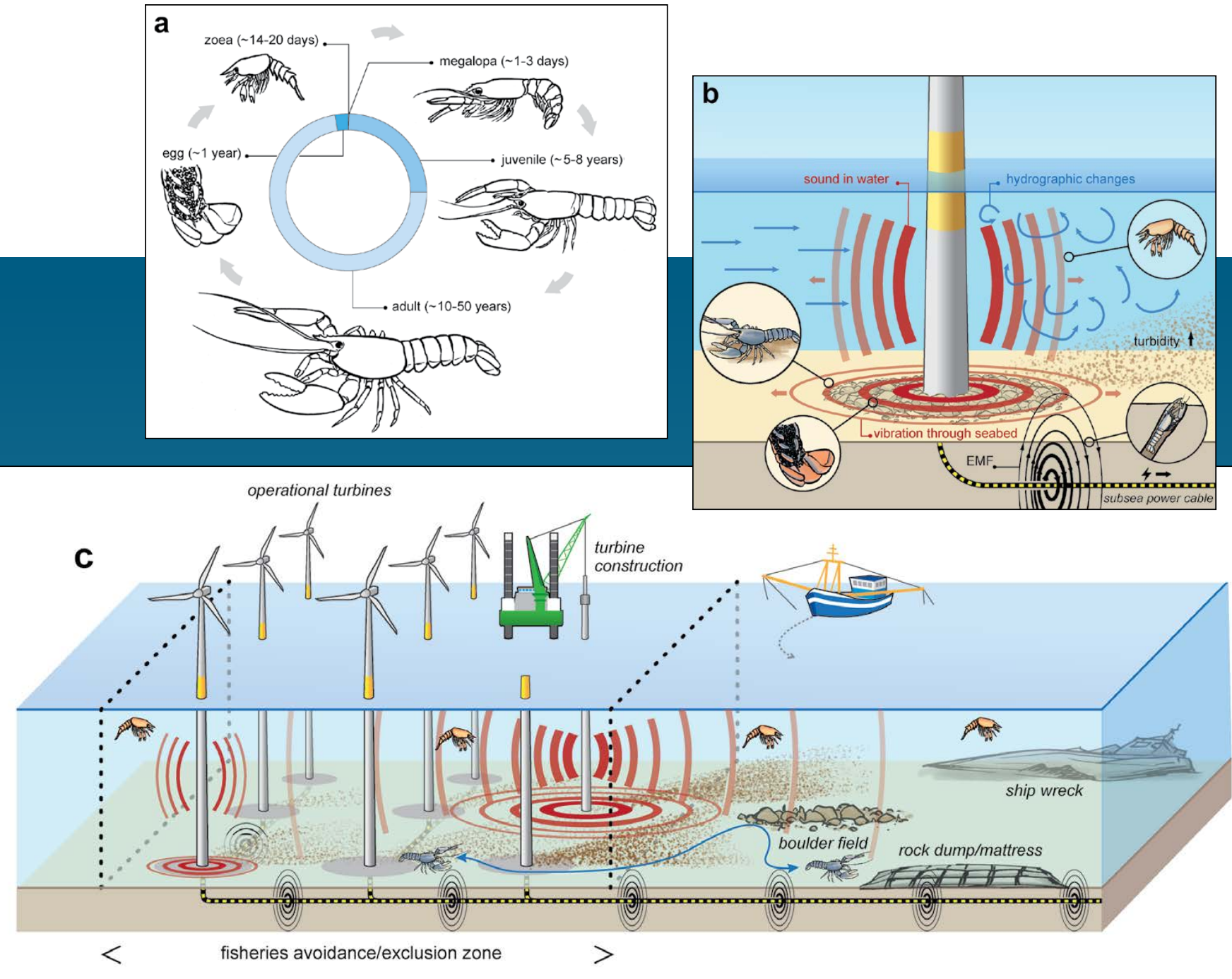

FIGURE B-1. Overview of the main effects on the different life stages of the lobster genus Homarus during the different offshore wind farm (OWF) development phases (not to scale). (a) Life cycle of Homarus spp. with five distinct life stages: embryonic egg, larval zoea, early benthic juvenile (megalopa), juvenile, and adult, with an indication of the duration of each life stage; the larval zoea has several molt stages. (b) and (c) Composite pictures of OWF effects during construction and operation on the different life stages of the lobster genus Homarus at a (b) turbine scale and at a (c) wider scale. Sound and vibration are transmitted during both construction and operation (Mooney et al., 2020, in this issue), though at a much lower intensity during operation. Construction sounds, which propagate over longer distances (particularly at low frequencies) compared to operational sounds, can have effects outside the OWF boundaries with decreasing intensity (c). Electromagnetic fields (EMFs) are only emitted when electrical current is transported through power cables. EMFs are emitted into the seabed and seawater from the infield cables (those extending between turbines in the array) and at higher intensities from the export cable (to the coast). Cables here are shown buried 1-2 m. The EMF extends several meters, and intensity decreases with distance above the seabed (Hutchison et al., 2020b, in this issue). Where the cables cannot be buried, they are protected by rocks or mattresses. Other factors that can affect the different life stages of the lobster are the artificial reef effect, fisheries avoidance (indicated by the broken arrow in front of the fishing vessel) and fisheries exclusion; changes in hydrography (including boundary layer mixing); and turbidity. Exclusion of fisheries can either be operational exclusion or regulatory exclusion, and can include the cable route to the coast. 
societal concerns and research questions in such programs can only be addressed by an iterative four-way interaction (i.e., society, including fishing communities; OWF industry; policy; and science). The ultimate goal is to translate societal concerns into a selection of tangible scientific questions. Figure 1 distinguishes two types of steps: (1) consultative steps that necessitate interaction among all four sectors (steps 1, 3, and 5), and (2) scientific reflection steps (steps 2, 4, and 6). The consultative steps set the context of the four-way interface and should inform and steer the scientific reflection steps. Such an approach has been successfully applied to defining a research program that targets mitigation of undesired impacts and promotion of desired impacts-as defined by society (in this case, nongovernmental environmental organizations) - of OWFs in a Belgian marine protected area and may thus be considered promising for also addressing fisheries-related aspects.

\section{Monitoring and Survey}

\section{Data Collection}

A key barrier to achieving coexistence between fisheries and OWFs is the lack of regionally integrated fisheries science monitoring and research programs to address fisheries interactions across the various scales of impacts and management activities (Methratta and Dardick, 2019). Formal monitoring of the environmental impacts of each offshore energy development is a requirement under many national legislative and/or regulatory frameworks (e.g., European Directives and the Australian Environment Protection and Biodiversity Conservation Act of 1999). As OWF developments increase, their cumulative effects on fish resources and/ or fisheries must be considered.

Recent environmental legislation and associated monitoring requirements are now shifting from a species-centric toward an ecosystem-based focus (e.g., the Marine Strategy Framework Directive in Europe). Furthermore, integrated assessments should be framed in societally meaningful terms, such as articulating whether seafood resource species in the area of an OWF will be ecologically sustainable over time (Wilding et al., 2017). Fisheries ecosystem services operate at varying scales, including transboundary. These scales are the same as fisheries scientific assessment and management scales currently practiced. Hence, understanding effects at the right scales underpins determination of impacts resulting from the interactions between OWFs and fisheries and therefore is essential for sustainable coexistence.

While the science highlights the need to consider ecosystem and transboundary scales, policies and consenting requirements in various national jurisdictions result in an uneven ability to effectively monitor and conduct fundamental research to understand fisheries and offshore wind interactions at the appropriate scales. In the United States, some but not all states have enacted fisheries research and monitoring policies that may be specific to state-level concerns and focused on individual projects despite the transboundary nature of fisheries and marine resources; the federal government only recommends guidelines for conducting fisheries monitoring activities (Methratta et al., 2020, in this issue). Europe exhibits a similar patchwork of monitoring and research requirements among nations. As stated, there are examples of science frameworks established to avoid the challenges described in Wilding et al. (2017), such as Belgium's environmental monitoring program, WinMon.BE (Degraer et al., 2019). However, examples of application of consistent and integrated monitoring programs across jurisdictions do not currently exist, and in some cases, fisheries monitoring of individual wind farm projects occurs where the federal government only recommends guidelines for conducting fisheries monitoring activities (e.g., USA; Methratta et al., 2020 , in this issue).

Typically, the objectives of fisheries management include maintaining stocks in order to provide optimum benefits and maximum sustainable yield. Fisheries science draws on the relatively wellunderstood aspects of species productivity (recruitment) and estimation of fishing mortality to achieve management objectives (Large et al., 2013). In some cases, decades of fisheries-dependent

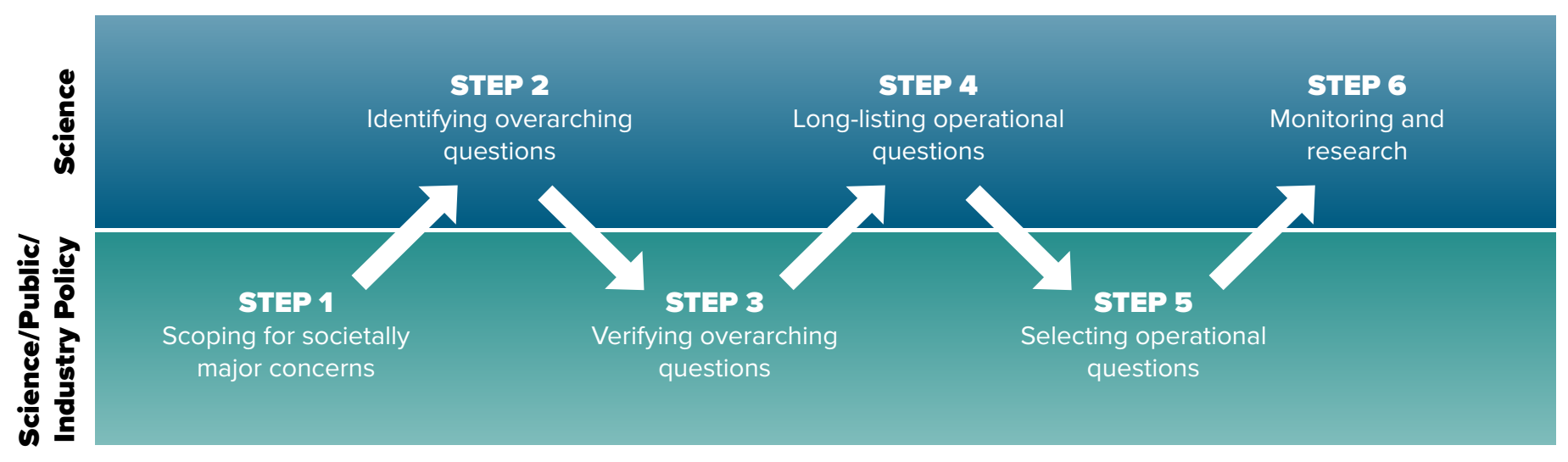

FIGURE 1. Schematic presentation of the stepwise approach toward linking societal concerns to society informed monitoring and research programs. 
and -independent data provide longterm trends in various fisheries stocks (in relation to fishing intensity and environmental variables). In addition, many fish stocks are statutorily monitored and afforded protection. For example, the Common Fisheries Policy in Europe and the Magnuson-Stevens Fishery Conservation and Management Act in the United States explicitly highlight spatial boundary delineation for fishery management. When assessing fisheryeffort changes that may be attributable to OWFs, it is important to interpret those changes in the context of the existing long-term trends and spatial boundaries (e.g., Addison et al., 2015).

To date, there are no policies or procedures in place that address the interactions between OWFs and existing fisheries, in particular, none related to resource surveys and the management advice they support. For example, in the US Atlantic, current fisheries survey designs and sampling methods designed to support stock assessments that inform fisheries management will not be sustainable within wind energy areas due to operational safety considerations and the incompatibility of survey methods. Understanding the changes to fishery distribution, abundance, and biological rates will be critical to adaptation of fisheries assessments, and any reduction in the accuracy and precision of appropriately scaled survey data will lead to increased uncertainty in fisheries stock assessments and quota advice. The adaptation and development of fisheries surveys used for stock management and advice will require the right level of resourcing and will also need to ensure data can be scaled. Upscaling from local to large marine ecosystem levels of organization is needed to understand interactions of OWFs with managed fish stocks, including changes in biological rates, species distribution, abundance, and food web dynamics. As OWFs occupy larger proportions of the world's available habitats for managed species, fisheries surveys need to both link with historical time series and evaluate current resources within and outside of managed areas.

Recognition of the need for regionally integrated offshore wind and fisheries science monitoring and research has inspired establishment of cross-border and cross-discipline collaborative groups that include representation from wind developer, fishing industry, government, and nongovernment stakeholders. The International Council on the Exploration of the Sea (ICES) is advancing transboundary, collaborative offshore wind and marine research through working groups that consider marine renewable energy, benthic interactions with offshore renewable energy, and, most recently, fisheries and offshore wind.

\section{Regulation}

At present, research and monitoring aimed at understanding the effects of OWFs on environmental receptors (including fisheries) require more consistent application to address legal, regulatory, and scientific issues (Wilding et al., 2017). Going forward, integrated and standardized frameworks for maritime governance of interconnected marine environments that may cross national borders will play a key role in supporting a sustainable ocean energy industry that implicitly involves OWF and fisheries considerations (Wright et al., 2016). Marine spatial planning, for example, is a framework in which the allocation of space for fisheries, wind development, and other marine sectors can be evaluated and operating rules (including coexistence) negotiated (Gill et al., 2018). However, permitting and licensing requirements, often involving different regulatory or advisory agencies within the same country, can result in bureaucratic complications that are exacerbated by a lack of dialogue among public institutions (Wright et al., 2016). For example, nearshore fishery and tourism activities and marine protected areas may be governed locally, whereas on a larger scale, shipping trade and tourist maritime routes are likely to occur in the vicinity of fishing and/or OWFs governed by state or federal regulations. In addition, without clear and effective communication regarding societal consequences, the development of maritime activities that change a land or seascape may not be socially acceptable. Consideration of how best to synergize laws, regulations, and policies across sectors and establish interindustry cooperation and consensus on codes and standards is recommended (Stuiver et al., 2016). It is also necessary to coordinate across nations and states when determining transboundary environmental effects, as well as across governance levels to account for the variable spatial and temporal scales over which changes to fisheries resources resulting from interaction with OWFs will occur (Gill et al., 2018).

\section{Fisheries Scientific}

\section{Investment Needs}

Part of the costs associated with OWF development relates to the licensing requirements and potential mitigation and/or compensation required. Altered access or transit routes to fishery sites may lead to potential loss of revenue and increased costs to other maritime activities. Added to this, the cost of environmental monitoring to satisfy licensing requirements in a highly dynamic environment with a poor knowledge base highlights the need to allocate and disperse monitoring and research toward more strategic approaches to knowledge enhancement (Wilding et al., 2017). To date, the focus of monitoring investments has been on a site-by-site basis. Unfortunately, this approach is flawed in concept when trying to apply the outputs to understanding the effects of OWFs on fisheries resource species as it does not properly account for cumulative and in-combination effects (Judd et al., 2015) at spatial scales directed toward addressing the "so what" question of meaningful change (Wilding et al., 2017). Hence, the finances for site monitoring could be allocated, in part, toward targeted data collection (sensu Figure 1) across jurisdictional boundaries as necessary to properly understand the implications of OWF interactions with the fisheries sector. 


\section{CONCLUSIONS}

Given current global offshore wind targets of 1.4 TW installed capacity by 2050 (GWEC, 2020), interactions between OWFs and fisheries are certain to increase. Promoting coexistence and addressing potential problems early on and at the right spatial scale requires that each of the topics covered here is appropriately considered and then addressed together. This will require the development of more holistic (social and ecosystem-level) approaches to management of interconnected marine environments that cross jurisdictions and national borders. To reduce uncertainty in the integrated approach also requires the delivery of accurate and precise scientific advice from fisheries and environmental monitoring systems adapted to OWFs and set at the right spatial and temporal scales. @

\section{REFERENCES}

Addison, P.F.E., L.B. Flander, and C.N. Cook. 2015. Are we missing the boat? Current uses of long-term biological monitoring data in the evaluation and management of marine protected areas. Journal of Environmental Management 149:148-56, https://doi.org/10.1016/j.jenvman.2014.10.023.

Ashley, M.C., S.C. Mangi, and L.D. Rodwell. 2014 The potential of offshore windfarms to act as marine protected areas-A systematic review of current evidence. Marine Policy 45:301-309, https://doi.org/10.1016/j.marpol.2013.09.002.

Barbut, L., B. Vastenhoud, L. Vigin, S. Degraer, F.A. Volckaert, and G. Lacroix. 2020. The proportion of flatfish recruitment in the North Sea potentially affected by offshore windfarms. ICES Journal of Marine Science 77(3):1,227-1,237, https://doi.org/ 10.1093/icesjms/fsz050.

Bergström, L., L. Kautsky, T. Malm, R. Rosenberg, M. Wahlberg, N.Å. Capetillo, and D. Wilhelmsson. 2014. Effects of offshore wind farms on marine wildlife-A generalized impact assessment. Environmental Research Letters 9(3):034012, https://doi.org/10.1088/1748-9326/9/3/034012.

Bohnsack, J.A. 1989. Are high densities of fishes at artificial reefs the result of habitat limitation or behavioral preference? Bulletin of Marine Science 44:631-645.

Botsford, L.W., J.C. Castilla, and C.H. Peterson. 1997. The management of fisheries and marine ecosystems. Science 277:509-515, https://doi.org/10.1126/ science. 277.5325.509.

Brickhill, M.J., S.Y. Lee, and R.M. Connolly. 2005 Fishes associated with artificial reefs: Attributing changes to attraction or production using novel approaches. Journal of Fish Biology 67:53-71, https://doi.org/10.1111/j.0022-1112.2005.00915.x.

Campbell, M., A. Pollack, T. Henwood, J. Provaznik, and M. Cook. 2012. Summary Report of the Red Snapper (Lutjanus campechanus) Catch During the 2011 Expanded Annual sSock Assessment (EASA). Southeast Data, Assessment, and Review, SEDAR31-DW17, $28 \mathrm{pp}$.
Carpenter, J.R., L. Merckelbach, U. Callies, S. Clark L. Gaslikova, and B. Baschek. 2016. Potential impacts of offshore wind farms on North Sea stratification. PLoS ONE 11(8):e0160830, https://doi.org/ $10.1371 /$ journal.pone. 0160830

Claisse, J.T., D.J. Pondella II, M. Love, L.A. Zahn, C.M. Williams, J.P. Williams, and A.S. Bull. 2014. Oil platforms off California are among the most productive marine fish habitats globally. Proceedings of the National Academy of Sciences of the United States of America 111(43):15,462-15,467, https://doi.org/10.1073/pnas.1411477111

Cooper, R.A., and J.R. Uzmann. 1980. Ecology of juvenile and adult Homarus. Pp. 97-142 in The Biology and Management of Lobsters, vol. II. J.S. Cobb and B.F. Phillips, eds, Academic Press, https://doi.org/ 10.1016/B978-0-08-091734-4.50010-X.

Daigle, S.T., J.W. Fleeger, J.H. Cowan, and P.-Y. Pascal. 2013. What is the relative importance of phytoplankton and attached macroalgae and epiphytes to food webs on offshore oil platforms? Marine and Coastal Fisheries: Dynamics, Management, and Ecosystem Science 5:53-64, https://doi.org/ 10.1080/19425120.2013.774301.

Dance, K.M., J.R. Rooker, J.B. Shipley, M.A. Dance, and R.J.D. Wells. 2018. Feeding ecology of fishes associated with artificial reefs in the northwest Gulf of Mexico. PLoS ONE 13:e0203873, https://doi.org/ 10.1371/journal.pone.0203873.

Dannheim, J., L. Bergström, S.N.R. Birchenough, R. Brzana, A. Boon, J. Coolen, J.-C. Dauvin, I. De Mesel, J. Derweduwen, and A. Gill. 2020. Benthic effects of offshore renewables: Identification of knowledge gaps and urgently needed research. ICES Journal of Marine Sciences 77:1,092-1,108, https://doi.org/10.1093/ icesjms/fsz018.

De Backer, A., H. Polet, K. Sys, B. Vanelslander, and K. Hostens. 2019. Fishing activities in and around Belgian offshore wind farms: Trends in effort and landings over the period 2006-2017. Pp. 31-46 in Environmental Impacts of Offshore Wind Farms in the Belgian Part of the North Sea: Marking a Decade of Monitoring, Research and Innovation. S. Degraer, R. Brabant, B. Rumes, and L. Vigin, eds, Royal Belgian Institute of Natural Sciences.

Debusschere, E., B. De Coensel, A. Bajek, D. Botteldooren, K. Hostens, J. Vanaverbeke, S. Vandendriessche, K. Van Ginderdeuren, M. Vincx, and S. Degraer. 2014. In situ mortality experiments with juvenile sea bass (Dicentrarchus labrax) in relation to impulsive sound levels caused by pile driving of windmill foundations. PLoS ONE 9:e109280, https://doi.org/10.1371/ journal.pone.0109280.

Degraer, S., R. Brabant, B. Rumes, and L. Vigin, eds. 2019. Environmental Impacts of Offshore Wind Farms in the Belgian Part of the North Sea Marking a Decade of Monitoring, Research and Innovation. Royal Belgian Institute of Natural Sciences, OD Natural Environment, Marine Ecology and Management, Brussels, $134 \mathrm{pp}$.

Degraer, S., D.A. Carey, J.W.P. Coolen, Z.L. Hutchison, F. Kerckhof, B. Rumes, and J. Vanaverbeke. 2020. Offshore wind farm artificial reefs affect ecosystem structure and functioning: A synthesis. Oceanography 33(4):48-57, https://doi.org/ 10.5670/oceanog.2020.405.

De Mesel, I., F. Kerckhof, A. Norro, B. Rumes, and S. Degraer. 2015. Succession and seasonal dynamics of the epifauna community on offshore wind farm foundations and their role as stepping stones for non-indigenous species. Hydrobiologia 756:37-50, https://doi.org/10.1007/ s10750-014-2157-1.

Dutch Ministry of Infrastructure and the Environment. 2016. Offshore Wind Energy Ecological Programme (WOZEP) Monitoring and Research Programme 2017-2021. Dutch Governmental Offshore Ecological Programme, $69 \mathrm{pp}$

Floeter, J., J.E.E. van Beusekom, D. Auch, U. Callies, J. Carpenter, T. Dudeck, S. Eberle, A. Eckhardt, D. Gloe, K. Hänselmann, and others. 2017.
Pelagic effects of offshore wind farm foundations in the stratified North Sea. Progress in Oceanography 156:154-173, https://doi.org/ 10.1016/j.pocean.2017.07.003.

Fowler, A.M., A.-M. Jørgensen, J.C. Svendsen, P.I. Macreadie, D.O.B. Jones, A.R. Boon, D.J. Booth, R. Brabant, E. Callahan, J.T. Claisse, and others. 2018. Environmental benefits of leaving offshore infrastructure in the ocean. Frontiers in Ecology and the Environment 16(10):571-578, https://doi.org/10.1002/fee.1827.

Gaines, S.D., C. White, M.H. Carr, and

S.R. Palumbi. 2010. Designing marine reserve networks for both conservation and fisheries management. Proceedings of the National Academy of Sciences of the United States of America 107(43):18,286-18,293, https://doi.org/ 10.1073/pnas.0906473107.

Gill, A.B. 2005. Offshore renewable energy: Ecological implications of generating electricity in the coastal zone. Journal of Applied Ecology 42:605-615, https://doi.org/10.1111/ j.1365-2664.2005.01060.x.

Gill, A.B., and D. Wilhelmsson. 2019. Fish. Chapter 5 in Wildlife and Wind Farms, Conflicts and Solutions, Vol. 3 Offshore: Potential Effects. M.R. Perrow, ed., Permagion Press.

Gill, A.B., S.N.R. Birchenough, A. Jones, A. Judd, S. Jude, A. Payo, and B. Wilson. 2018. Environmental implications of offshore energy. Pp. 132-169 in Offshore Energy and Marine Spatial Planning. K.L. Yates and C.J.A. Bradshaw, eds, London, Routledge, https://doi.org/ 10.4324/9781315666877-9.

Gill, A.B., and M. Desender. 2020. Risk to animals from electromagnetic fields emitted by electric cables and marine renewable energy devices. Pp. 86-103 in OES-Environmental 2020 State of the Science Report: Environmental Effects of Marine Renewable Energy Development Around the World. No. PNNL-29976CHPT5 Pacific Northwest National Lab, Richland, WA, 18 pp. https://doi.org/10.2172/1633088.

GWEC (Global Wind Energy Council). 2020. Global Offshore Wind Report 2020.102 pp.

Gusatu, L.F., C. Yamu, C. Zuidema, and A. Faaij. 2020 A spatial analysis of the potentials for offshore wind farm locations in the North Sea region: Challenges and opportunities. ISPRS International Journal of Geo-Information 9(2):96, https://doi.org/10.3390/ ijgi9020096.

Harrison, H.B., D.H. Williamson, R.D. Evans, G.R. Almany, S.R. Thorrold, G.R. Russ K.A. Feldheim, L. Van Herwerden, S. Planes, M. Srinivasan, and others. 2012. Larval export from marine reserves and the recruitment benefit for fish and fisheries. Current Biology 22:1,023-1,028, https://doi.org/10.1016/j.cub.2012.04.008.

Hawkins, A.D., A.E. Pembroke, and A.N. Popper. 2015 Information gaps in understanding the effects of noise on fishes and invertebrates. Reviews in Fish Biology and Fisheries 25(1):39-64, https://doi.org/ 10.1007/s11160-014-9369-3.

Hooper, T., M. Ashley, and M. Austen. 2017. Capturing benefits: Opportunities for the co-location of offshore energy and fisheries. Pp. 189-213 in Offshore Energy and Marine Spatial Planning. K.L. Yates and C.J.A. Bradshaw, eds, Routledge, https://doi.org/ 10.4324/9781315666877-11.

Hutchison, Z.L., A.B. Gill, P. Sigray, H. He, and J.W. King. 2020a. Anthropogenic electromagnetic fields (EMF) influence the behaviour of bottom-dwelling marine species. Scientific Reports 10(1):1-15, https://doi.org/10.1038/ s41598-020-60793-x.

Hutchison, Z.L., D.H. Secor, and A.B. Gill. 2020.

The interaction between resource species and electromagnetic fields associated with electricity production by offshore wind farms. Oceanography 33(4):96-107, https://doi.org/ 10.5670/oceanog.2020.409. 
Judd, A.D., T. Backhaus, and F. Goodsir. 2015. An effective set of principles for practical implementation of marine cumulative effects assessment. Environmental Science and Policy 54:254-262, https://doi.org/10.1016/j.envsci.2015.07.008.

Krone, R., L. Gutow, T. Brey, J. Dannheim, and A. Schroder. 2013. Mobile demersal megafauna at artificial structures in the German BightLikely effects of offshore wind farm development. Estuarine Coastal and Shelf Science 125:1-9, https://doi.org/10.1016/j.ecss.2013.03.012.

Krone, R., G. Dederer, P. Kanstinger, P. Krämer, and C. Schneider. 2017. Mobile demersal megafauna at common offshore wind turbine foundations in the German Bight (North Sea) two years after deployment-Increased production rate of Cancer pagurus. Marine Environmental Research 123:53-61, https://doi.org/10.1016/ .marenvres.2016.11.011.

Langhamer, O. 2012. Artificial reef effect in relation to offshore renewable energy conversion: State of the art. The Scientific World Journal 2012:1-8, https://doi.org/10.1100/2012/386713.

Large, S.I., G. Fay, K.D. Friedland, and J.S. Link. 2013. Defining trends and thresholds in responses of ecological indicators to fishing and environmental pressures. ICES Journal of Marine Science 70:755-767, https://doi.org/10.1093/ icesjms/fst067.

Lester, S.E., B.S. Halpern, K. Grorud-Colvert, J. Lubchenco, B.I. Ruttenberg, S.D. Gaines, S. Airamé, and R.R. Warner. 2009. Biological effects within no-take marine reserves: A global synthesis. Marine Ecology Progress Series 384:33-46, https://doi.org/10.3354/meps08029.

Lindberg, W. J. 1997. Can science resolve the attraction-production issue? Fisheries 22:10-13.

Mavraki, N. 2020. On the Food-Web Ecology of Offshore Wind Farms, the Kingdom of Suspension Feeders. PhD thesis, Ghent University, 276 pp.

Methratta, E.T., and W.R. Dardick. 2019. MetaAnalysis of Finfish Abundance at Offshore Wind Farms. Reviews in Fisheries Science \& Aquaculture 27:242-260, https://doi.org/10.1080/ 23308249.2019.1584601.

Methratta, E.T., A. Hawkins, B.R. Hooker, A. Lipsky, and J.A. Hare. 2020. Offshore wind development in the Northeast US Shelf Large Marine Ecosystem: Ecological, human, and fishery management dimensions. Oceanography 33(4):16-27, https://doi.org/10.5670/oceanog.2020.402.

Moland, E., E.M. Olsen, H. Knutsen, J.A. Knutsen, S.E. Enersen, C. André, and N.C. Stenseth. 2011. Activity patterns of wild European lobster Homarus gammarus in coastal marine reserves: Implications for future reserve design. Marine Ecology Progress Series 429:197-207, https://doi.org/10.3354/ meps09102.

Mooney, T.A., M.H. Andersson, and J. Stanley. 2020. Acoustic impacts of offshore wind energy on fishery resources: An evolving source and varied effects across a wind farm's lifetime. Oceanography 33(4):82-95, https://doi.org/ 10.5670/oceanog.2020.408.

Murawski, S.A., S.E. Wigley, M.J. Fogarty, P.J. Rago, and D.G. Mountain. 2005. Effort distribution and catch patterns adjacent to temperate MPAs. ICES Journal of Marine Science 62:1,150-1,167, https://doi.org/10.1016/j.icesjms.2005.04.005.

O'Keeffe, A., and C. Haggett. 2012. An investigation into the potential barriers facing the development of offshore wind energy in Scotland: Case study - Firth of Forth offshore wind farm. Renewable and Sustainable Energy Reviews 16:3,711-3,721, https://doi.org/10.1016/j.rser.2012.03.018.

Paxton, A., K. Shertzer, N. Bacheler, T. Kellison, K. Riley, and J. Taylor. 2020. Meta-analysis reveals artificial reefs can be effective tools for fish community enhancement but are not one-size-fitsall. Frontiers in Marine Science 7, https://doi.org/ 10.3389/fmars.2020.00282.
Popper, A.N., and A.D. Hawkins. 2019. An overview of fish bioacoustics and the impacts of anthropogenic sounds on fishes. Journal of Fish Biology 94(5):692-713, https://doi.org/10.1111/ jfb.13948.

Raoux, A., S. Tecchio, J.-P. Pezy, G. Lassalle, S. Degraer, D. Wilhelmsson, M. Cachera, B. Ernande, C. Le Guen, M. Haraldsson, and others. 2017. Benthic and fish aggregation inside an offshore wind farm: Which effects on the trophic web functioning? Ecological Indicators 72:33-46, https://doi.org/10.1016/j.ecolind.2016.07.037.

Reeves, D.B., E.J. Chesney, R.T. Munnelly, D.M. Baltz, and K. Maiti. 2019. Trophic ecology of sheepshead and stone crabs at oil and gas platforms in the Northern Gulf of Mexico's hypoxic zone. Transactions of the American Fisheries Society 148:324-338, https://doi.org/10.1002/ tafs.10135.

Reubens, J.T., S. Degraer, and M. Vincx. 2014. The ecology of benthopelagic fishes at offshore wind farms: A synthesis of 4 years of research. Hydrobiologia 727:121-136, https://doi.org/10.1007/ s10750-013-1793-1.

Roberts, L., and M. Elliott. 2017. Good or bad vibrations? Impacts of anthropogenic vibration on the marine epibenthos. Science of the Total Environment 595:255-268, https://doi.org/10.1016/ j.scitotenv.2017.03.117.

SCEMFIS (Science Center for Marine Fisheries) 2020. Review of "Vineyard Wind 1 Offshore Wind Energy Project Supplement to the Draft Environmental Impact Statement." E.N. Powell, ed. https://scemfis.org/wp-content/uploads/2020/07/ wind report final-1.pdf.

Schulze, A., D.L. Erdner, C.J. Grimes, D.M. Holstein, and M.P. Miglietta. 2020. Artificial reefs in the Northern Gulf of Mexico: Community ecology amid the "ocean sprawl." Frontiers in Marine Science 7:447, https://doi.org/10.3389/ fmars.2020.00447.

Stuiver, M., K. Soma, P. Koundouri, S. Van den Burg, A. Gerritsen, T. Harkamp, N. Dalsgaard, F. Zagonari, R. Guanche, J.-J. Schouten, and others. 2016. The governance of multi-use platforms at sea for energy production and aquaculture: Challenges for policy makers in European seas. Sustainability 8(4):333, https://doi.org/10.3390/ su8040333.

Taormina, B., J. Bald, A. Want, G. Thouzeau, M. Lejart, N. Desroy, and A. Carlier. 2018. A review of potential impacts of submarine power cables on the marine environment: Knowledge gaps, recommendations and future directions. Renewable and Sustainable Energy Reviews 96:380-391, https://doi.org/10.1016/j.rser.2018.07.026.

van Berkel, J., H. Burchard, A. Christensen, L.O. Mortensen, O. Svenstrup Petersen, and F. Thomsen. 2020. The effects of offshore wind farms on hydrodynamics and implications for fishes. Oceanography 33(4):108-117, https://doi.org/ 10.5670/oceanog.2020.410.

Wahle, R.A. 1992. Body-size dependent antipredator mechanisms of the American lobster. Oikos 65(1):52-60, https://doi.org/10.2307/ 3544887.

Wang, J., X. Zou, W. Yu, D. Zhang, and T. Wang 2019. Effects of established offshore wind farms on energy flow of coastal ecosystems: A case study of the Rudong offshore wind farms in China. Ocean and Coastal Management 171:111-118, https://doi.org/10.1016/j.ocecoaman.2019.01.016. Wilding, T.A., A.B. Gill, A. Boon, E. Sheehan, J.C. Dauvin, J.P. Pezy, F. O'Beirn, U. Janas, L. Rostin, and I. De Mesel. 2017. Turning off the DRIP ('Datarich, information-poor')-Rationalising monitoring with a focus on marine renewable energy developments and the benthos. Renewable and Sustainable Energy Reviews 74:848-859, https://doi.org/10.1016/j.rser.2017.03.013.

WindEurope. 2020. Offshore Wind in Europe, Key Trends and Statistics 2019. WindEurope, Brussels, Belgium, $40 \mathrm{pp}$.
Worm, B., R. Hilborn, J.K. Baum, T.A. Branch, J.S. Collie, C. Costello, M.J. Fogarty, E.A. Fulton, J.A. Hutchings, S. Jennings, and others. 2009 Rebuilding global fisheries. Science 325:578-585, https://doi.org/10.1126/science.1173146.

Wright, G., A.M. O'Hagan, J. de Groot, Y. Leroy, N. Soininen, R. Salcido, M.A. Castelos, S. Jude, J. Rochette, and S. Kerr. 2016. Establishing a legal research agenda for ocean energy. Marine Policy 63:126-134, https://doi.org/10.1016/ j.marpol.2015.09.030.

\section{ACKNOWLEDGMENTS}

We thank the National Academies of Science, Engineering, and Medicine and the guest editors for inviting us to author this paper as a contribution to the special issue. Hendrik Gheerardyn is thanked for designing Figure B-1. Thanks to Hans Hillewaert for providing the background photo for the title page of the paper. Anna Mercer (NOAA) is thanked for reviewing and providing comments on the paper. Note that the contents of the paper reflect the authors' considered opinions and not the opinions of our respective organizations.

\section{AUTHORS}

Andrew B. Gill (andrew.gill@cefas.co.uk) is Principa Scientist, Centre for Environment, Fisheries and Aquaculture Science, Lowestoft, Suffolk, UK. Steven Degraer is Prime Work Lead, Royal Belgian Institute of Natural Sciences, Operational Directorate Natural Environment, Marine Ecology and Management, Brussels, Belgium. Andrew Lipsky is Fisheries and Offshore Wind Lead, NOAA Fisheries, Northeast Fisheries Science Center, Woods Hole, MA, USA. Ninon Mavraki is a marine ecologist at the Royal Belgian Institute of Natural Sciences, Operational Directorate Natural Environment, Marine Ecology and Management, Brussels, Belgium, and Wageningen Marine Research, Den Helder, the Netherlands. Elizabeth Methratta is Fisheries Biologist, IBSS Corporation in support of NOAA Fisheries, Northeast Fisheries Science Center, Woods Hole, MA, USA. Robin Brabant is Research Scientist, Royal Belgian Institute of Natural Sciences, Operational Directorate Natural Environment, Marine Ecology and Management, Brussels, Belgium.

\section{ARTICLE CITATION}

Gill, A.B., S. Degraer, A. Lipsky, N. Mavraki, E. Methratta, and R. Brabant. 2020. Setting the context for offshore wind development effects on fish and fisheries. Oceanography 33(4):118-127, https://doi.org/10.5670/oceanog.2020.411.

\section{COPYRICHT \& USAGE}

This is an open access article made available under the terms of the Creative Commons Attribution 4.0 International License (https://creativecommons.org/ licenses/by/4.0/), which permits use, sharing, adaptation, distribution, and reproduction in any medium or format as long as users cite the materials appropriately, provide a link to the Creative Commons license, and indicate the changes that were made to the original content. 